\title{
Nephroprotective effect of cerium oxide nanoparticles on cyclophosphamide-induced nephrotoxicity via anti- apoptotic and antioxidant properties in BALB/c mice
}

\author{
Maedeh Hamzeh 1, Fereshteh Talebpour Amiri 2,* , Saeed Yaghubi Beklar ${ }^{1}$, Seyed Jalal Hosseinimehr ${ }^{3}$ \\ 1 Student Research Committee, Faculty of Medicine, Mazandaran University of Medical Sciences, Sari, Iran. \\ 2 Department of Anatomy, Faculty of Medicine, Molecular and Cell Biology Research Center, Mazandaran University \\ of Medical Sciences, Sari, Iran. \\ 3 Department of Radiopharmacy, Faculty of Pharmacy, Mazandaran University of Medical Sciences, Sari, Iran \\ * Correspondence: ftalebpour@mazums.ac.ir (F.T.A.); ORCID No: 0000-0001-9847-3401; Mobile: 00989113116413; Fax: \\ 01133543248; Current Adress: Fereshteh Talebpour Amiri, Department of Anatomy, Molecular and Cell Biology \\ Research Center, Mazandaran University of Medical Sciences, Sari, Iran; Postal address: Khazar Boulevard, Sari, Iran. \\ Postal code: 4847191971.
}

Received: 18 November 2017 / Revised: 16 December 2017 / Accepted: 21 December 2017

\begin{abstract}
Cyclophosphamide [CP], as alkylating agents has side effects such as nephrotoxicity. Cerium oxide nanoparticles [nanoceria; $\mathrm{NC}$ ], as an antioxidant, are effective at reduction oxidative stress. This study evaluated the protective effect of nanoceria in nephrotoxicity induced CP. $32 \mathrm{BALB} / \mathrm{c}$ mice were randomly divided into four equal groups. Control, NC, CP and NC+CP. NC and CP injected intraperitoneally respectively in dose of $100 \mu \mathrm{g} / \mathrm{kg}$ for $3 \mathrm{days}$ and $200 \mathrm{mg} / \mathrm{kg}$ single dose on 3th day of study. Two days after the final treatment, histochemical, serum biochemical, histopathological and immunohistochemical examinations were performed for determination effects of NC on nephrotoxicity. Oxidative stress and renal injury induced in $\mathrm{CP}$ treated mice were proved by the significantly elevation of urea and creatinine and alteration in oxidative stress markers [MDA and GSH levels]. Consequently, histopathological changes and apoptosis were markedly increased. NC was able to reduce MDA, urea, creatinine and increase GSH content. In addition, NC pretreatment could alleviated immunoreactivity of caspase-3. NC revealed a strong antioxidant in nephrotoxicity following CP treatment. This study suggests that NC through antioxidant and antiapoptotic properties have protective effect against CP-induced nephrotoxicity.
\end{abstract}

KEYWORDS: Cyclophosphamide; Nanoceria; Oxidative stress; Nephrotoxicity; Caspase-3.

\section{INTRODUCTION}

Cyclophosphamide [CP], as a cytotoxic alkylating agent used in treatment cancers and as an immunosuppressive agent in organ transplantation and autoimmune diseases [1]. Despite its usefulness, its use due to undesirable effects, including nephrotoxicity, associated with restrictions [2]. Phosphoramide mustard and acrolein, as two of major metabolites of CP induce toxicity [3, 4]. These metabolites with alkylation nucleophilic sites in DNA, RNA, and protein cause toxicity [5]. Generation of free radicals and oxidative stress is the main mechanism for inducing toxicity [3]. The side effects of $\mathrm{CP}$ in cancer patients are glomerular and tubular dysfunction, renal papillary necrosis and pyelonephritis [2]. In CP-induced nephrotoxicity increase plasma CREA [creatinine] and BUN [Blood Urea Nitrogen] levels, which indicates renal glomerular dysfunction. However, despite the severe toxicity of cyclophosphamide in experimental animal and human studies [6,7], still clinicians prescribe it as the first line treatment for cancer patients. Also, exogenous antioxidant agents were revealed effective in mitigation of $\mathrm{CP}$ nephrotoxicity $[6,8]$.

Nowadays, Nanoparticles [NPs] compounds have been used extensively in different diseases. Cerium oxide nanoparticles [Ceo2 NPs, nanoceria, NC] with structural characteristics between 1 to $100 \mathrm{~nm}$ have 
protective effects at low concentrations and toxic effects at high concentrations. In fact, their antioxidant property are considered to be in the treatment of diseases [9]. In recent years, use of nanoparticles, nanomedicine and nanotoxicology has attracted attention of a wide range of researchers [10]. NC, as a catalyst, mimics enzymatic antioxidants such as superoxide dismutase and catalase. The antioxidant potential of NC is comparable with superoxide dismutase [11, 12]. This nanoparticle with scavenging free radicals protects organs against oxidative stress [13] and decreases attraction of inflammatory cells [14]. Also, NC, as a regular antioxidant diminishes oxidative disruption of membranes and maintain the integrity of the cell membrane [15]. Protective effect NC has been demonstrated against damage induce with radiation [16, 17]. On the other, Synergistic effects of NC and doxorubicin show on cytotoxicity, production ROS and oxidative injury in tumoral cells [18]. In previous study proved anti-apoptotic property of NC on injury following oxidative stress $[19,20]$. However, the protective effect of the NC on CP-induced nephrotoxicity has been not established. The aim of this study was to determine whether NC can protect nephrotoxicity induced $\mathrm{CP}$. The extent of the protective effect of $\mathrm{NC}$ against $\mathrm{CP}$-induced nephrotoxicity and its antioxidant and anti-apoptotic effects were determined by studying the oxidative stress markers, renal injury indexes [CREA and BUN], histopathology and immunohistochemistry assays in mice.

\section{RESULTS}

\subsection{Effects of NC on oxidative stress markers of kidney tissue in $\mathrm{CP}$ treated mice}

The malondialdehyde [MDA] and Glutathione (GSH) levels in kidney tissue are presented in figure 1. The MDA level, as the final product of lipid peroxidation [LPO], was significantly increased, and Glutathione [GSH] content was decreased in CP treated group compared with control group (respectively $p<0.001$ and $p<0.001)$. NC pretreatment in CP treated mice was significantly decreased the MDA and significantly increased GSH content when compared with CP alone group (respectively $p \leq 0.015$ and $p<$ 0.001).

MDA

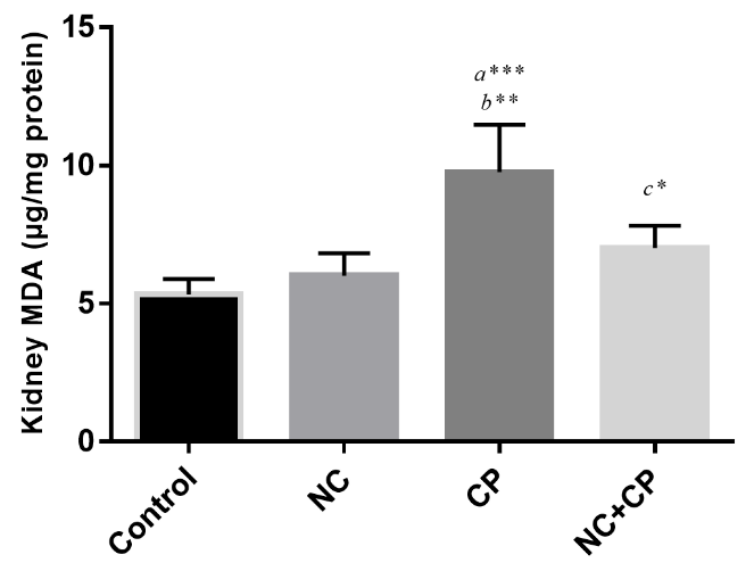

GSH

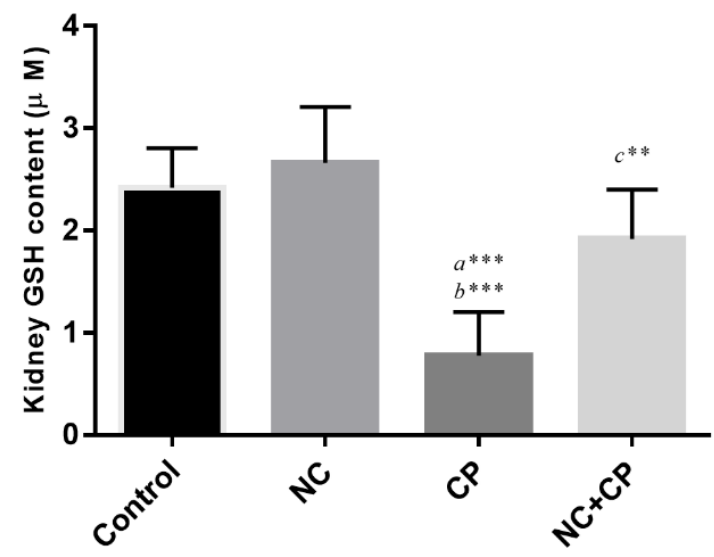

Figure 1. Effect of NC on MDA and GSH levels in CP-treated mice.

Mice were treated with CP showed an increase in the MDA level and decrease in GSH content compared with control group. Treatment with NC in CP treated mice significantly decreased concentration of MDA and increased GSH content in the renal tissue compared with $\mathrm{CP}$ group. All values are expressed as mean $\pm \mathrm{SD}$. a significant vs. control, $\mathrm{b}$ significant vs. NC and c significant vs. $\mathrm{CP}$ groups. *; $\mathrm{P}<0.05$, **; $\mathrm{P}<0.01$, *** and $\mathrm{P}<0.001$. NC; Nanoceria, $\mathrm{CP}$; Cyclophosphamide, MDA; Malondialdehyde, GSH; Glutathione.

\subsection{Effects of NC on serum BUN and CREA in CP treated mice}

Serum creatinine and BUN levels, as injury markers of kidney, measured in the present study. Figure 2 presented the effect of $\mathrm{CP}$ and $\mathrm{NC}$ on the blood concentration of these markers. The levels of the serum BUN and CREA were significantly higher in the CP treated mice at a dose of $200 \mathrm{mg} / \mathrm{kg}$ of body weight, when compared to the control group (respectively $p<0.001$ and $p<0.001$ ). NC pretreatment in CP treated mice significantly decreased the level of these markers compared to the CP alone group (respectively $p \leq 0.017$ and $p \leq 0.02$ ). 


\section{BUN}

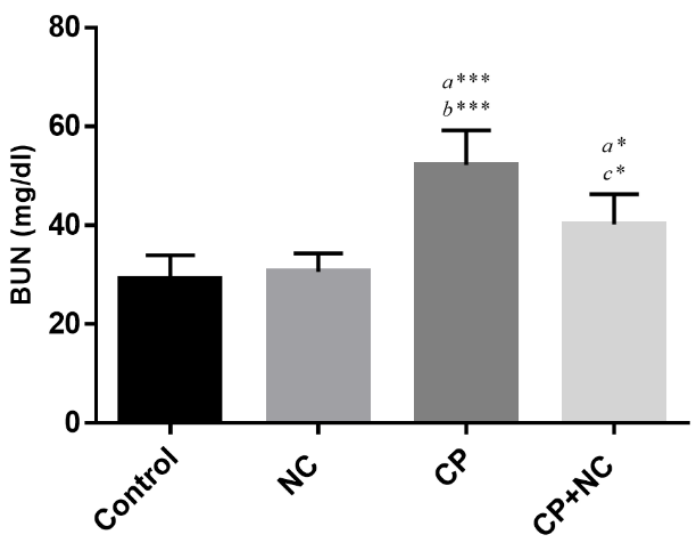

Creatinine

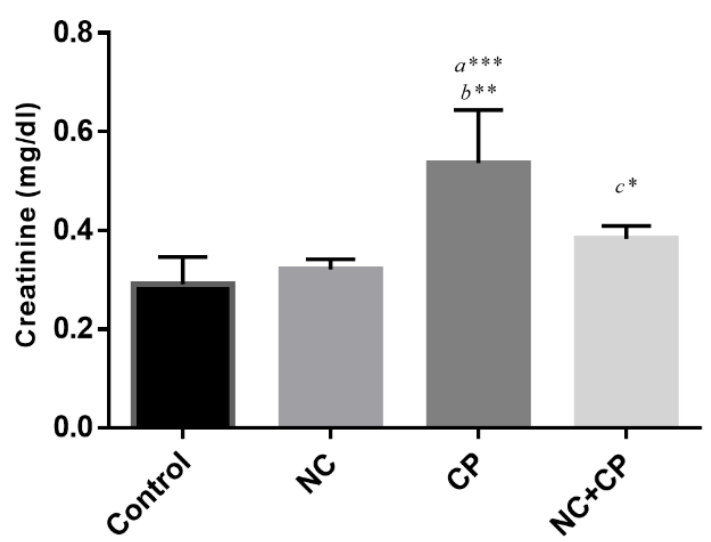

Figure 2. Effect of NC on serum marker enzymes of kidney injury in CP-treated mice.

All values are expressed as mean $\pm \mathrm{SD}$. Mice were treated with CP showed an increase in the serum creatinine and BUN levels. Pre and post treatment with NC significantly decreased these markers in the serum. a significant vs. control, $b$ significant vs. NC and c significant vs. $\mathrm{CP}$ groups. ${ }^{*} ; \mathrm{P}<0.05,{ }^{* *} ; \mathrm{P}<0.01,{ }^{* * *}$ and $\mathrm{P}<0.001$. NC; Nanoceria, $\mathrm{CP}$; Cyclophosphamide, BUN; Blood urea nitrogen, CREA; Creatinine.

\subsection{Effect of NC on histopathology of kidney tissue in CP treated mice}

The effects of $\mathrm{CP}$ on histological structure are presented in Figure 3. Glomerular and tubular structure of kidneys were no histopathological changes in the control group (A) and NC alone group (B). In contrast, $\mathrm{CP}$ treatment induced degeneration epithelial cells, leukocytes infiltration, tubular and glomeruli atrophy, widened Bowman's space and thickened basement membrane of Bowman's space, pyknotic nuclei and basophilic of renal epithelium, the appearance of protein columna [casts] in the renal proximal tubules in $\mathrm{CP}$ treated mice when compared with the control group, indicating the nephrotoxicity of $\mathrm{CP}$. (C). The results of the histopathology improved kidney damage in $\mathrm{CP}+\mathrm{NC}$ group (D). NC pretreatment was able to ameliorate these histopathological alternations. Renal injury scores, as shown in Figure 4, in CP group had a higher score than other groups. The injury score of $\mathrm{CP}$ group was $2.5 \pm 0.55$, while the $\mathrm{CP}+\mathrm{NC}$ group scored $1.5 \pm 0.55$, and this difference was significant $(p \leq 0.02)$.

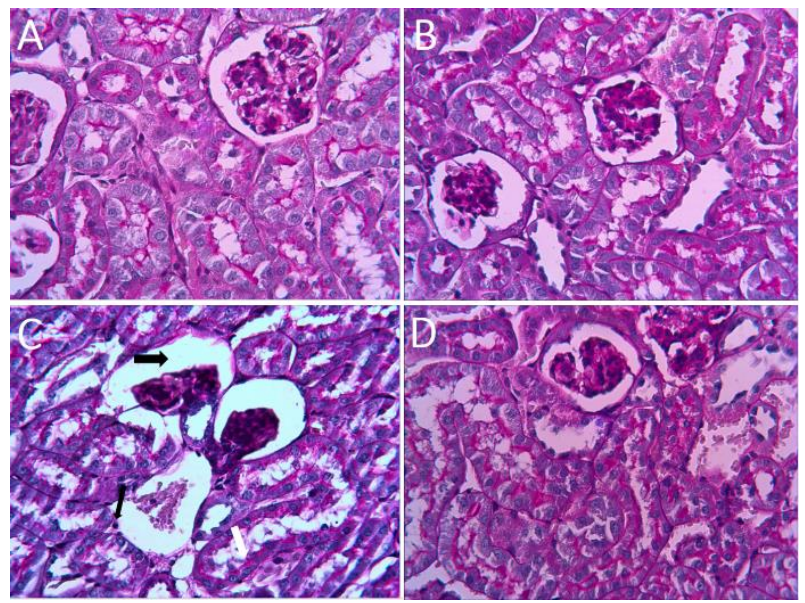

Figure 3. Photomicrographs of mice kidney in all groups.

(A) Control group; (B) NC alone treated group showed normal renal histoarchitecture; (C) CP group showed dilatation, vacuolation, degeneration (white arrow), epithelial desquamation (thin black arrow), widened Bowman's space (thick black arrow), necrosis, intraluminal cast formation in the proximal tubules; (D) histopathological finding in the NC + $\mathrm{CP}$ group improved which is comparable to CP group. (PAS staining, mag. $\times$ 400). NC; Nanoceria, CP; Cyclophosphamide. 


\section{Renal Injury Score}

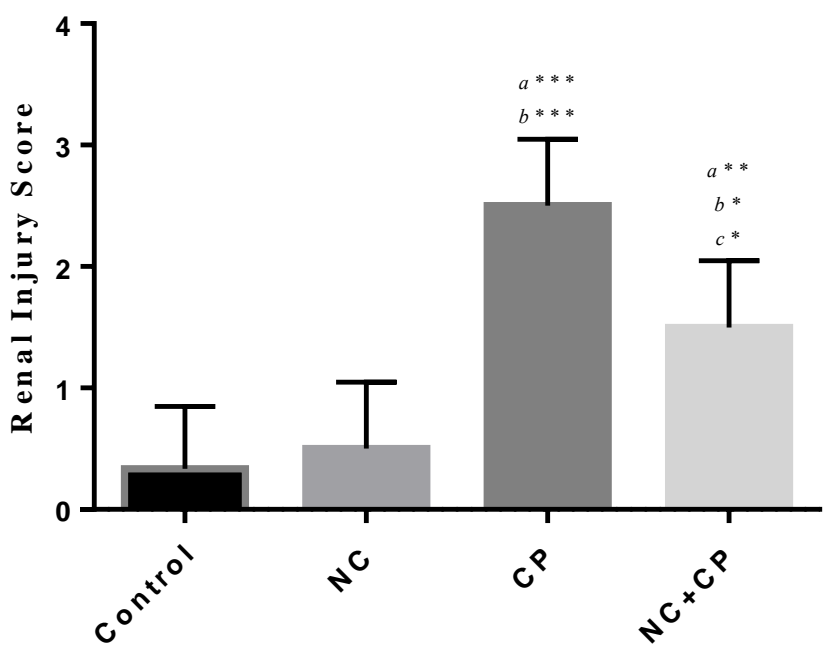

Figure 4. Tubular injury was scored in renal tissues.

Data are presented as Mean \pm SD. The most score was for CP group. $a$ significant vs. control, $b$ significant vs. NC and c significant vs. CP groups. *; $P<0.05,{ }^{* *} ; P<0.01,{ }^{* * *}$ and $P<0.001$. NC decreased renal injury score in the $\mathrm{NC}+\mathrm{CP}$ group. NC; Nanoceria, $\mathrm{CP}$; Cyclophosphamide.

\subsection{Effect of NC on immunoreactivity of caspase-3 of kidney tissue in $\mathrm{CP}$ treated mice}

Immunohistochemical photomicrographs of the kidney are showed in Figure 5. Caspase-3 positive cells were stained as brown color. caspase- 3 immunoreactivity was undetectable in section of kidneys in the control and NC groups. Increase immunoreactivity level of caspase-3 demonstrated marked in CP-treated mice. Immunoreactivity staining was observed severe to moderate in the cytoplasm of tubular epithelial cells in the cortex or medulla of kidney and the visceral layer of Bowman's capsule (A). Immunoreactivity staining of caspase-3 in epithelial cells in CP treated mice with NC $(100 \mu \mathrm{g} / \mathrm{kg})$ displayed marked reduction in staining for caspase-3 (B), compared to $\mathrm{CP}$ alone group. The histograms of the semi-quantitative analysis of immunohistochemical detection of caspase-3 in all groups are shown in Figure 6. The most intense immunoreactivity of caspase-3 was confirmed by semi-quantitative analysis in CP treated mice (19.73 \pm 3.96$)$ compared with the other groups $(p<0.05)$. NC treatment decreased severity of immunoreactivity of caspase-3 in CP treated mice (14.53 \pm 2.63$)$. Immunoreactivity level of caspase-3 in the control group was similar to NC alone group.
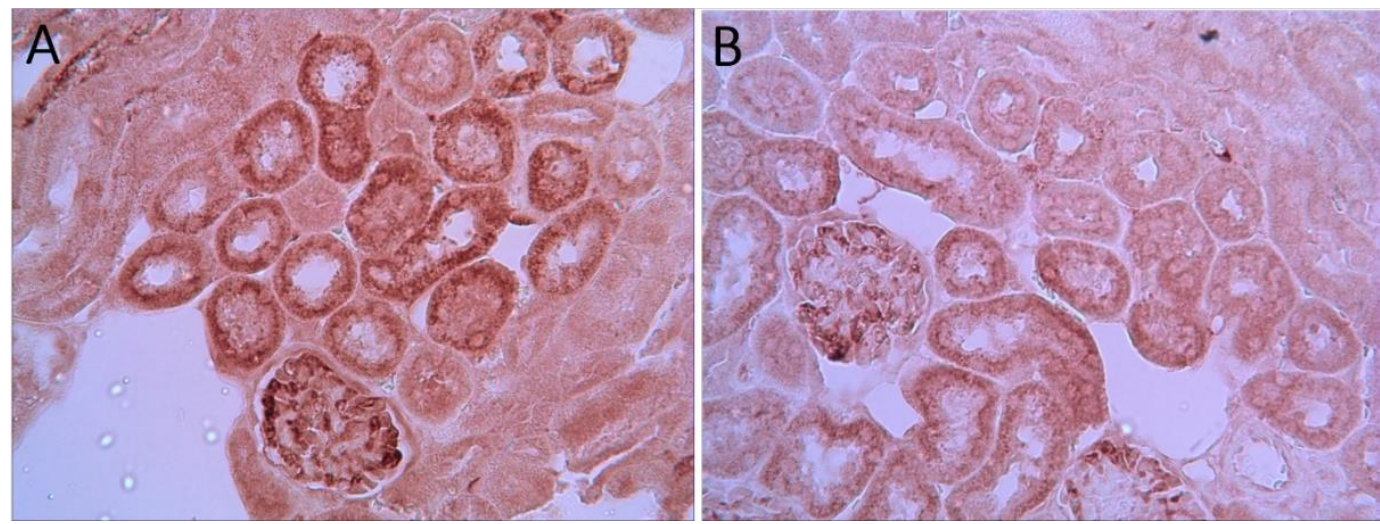

Figure 5. Immunohistochemical staining of caspase-3 in mice kidney:

(A) CP treated group showed a significant increase in caspase-3 immunoreactivity in the cytoplasm of tubular epithelial cells and visceral layer of Bowman's capsule;

(B) $\mathrm{NC}+\mathrm{CP}$ group demonstrated a significant reduction in caspase- 3 immunostaining. Brown color indicates caspase3 positivity. (Magnification $\times 40$ ), NC; Nanoceria, $C P$; Cyclophosphamide. 


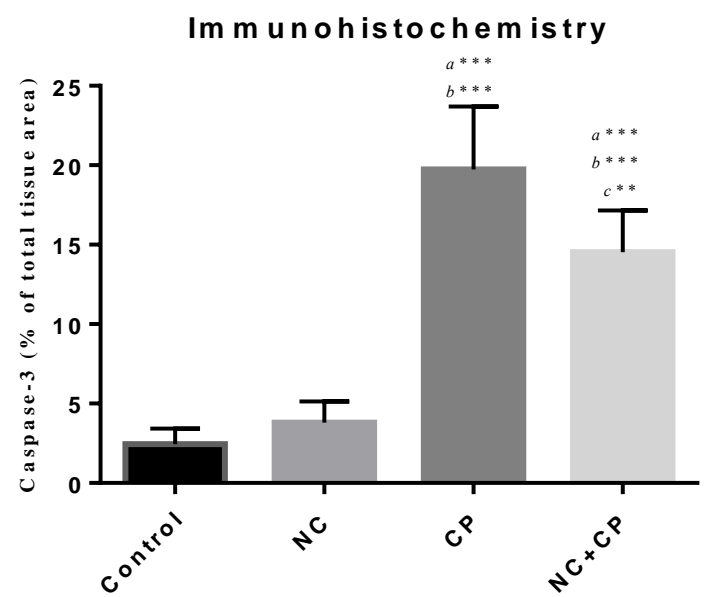

Figure 6. Densitometry analysis of immunohistochemical staining for caspase-3.

Data were presented as a percentage of total tissue area. Immunoreactivity level of caspase- 3 in the NC alone group was slightly higher compared to the control group, but this increase was not significant. $a$ significant vs. control, $b$ significant vs. NC and c significant vs. CP groups. ${ }^{*} ; P<0.05,{ }^{* *} ; P<0.01, * * *$ and $P<0.001$. Data are presented as Mean $\pm \mathrm{SD}$. NC; Nanoceria, CP; Cyclophosphamide.

\section{DISCUSSION}

Cyclophosphamide, as a main antineoplastic agent and immune suppressor have side effects on organs by its toxic metabolites [21] .The kidney is the target organ affected by $\mathrm{CP}$ [2] . Most of metabolites of $\mathrm{CP}$ are excreted through the urine. In during the excretion process, metabolites of $\mathrm{CP}$ induce nephrotoxicity [22]. A strategy is needed to reduce the side effects of anticancer drugs with the maintenance of its chemotherapeutic efficacy. To estimate potential therapeutic of nanoceria as an antioxidant, we investigated serum biochemical, histochemical, histophatological and immunohistochemical assays in nephrotoxicity induced CP. In this study, the parameters of oxidative stress, serum markers of renal injury were significantly increased in CP treated mice compared to the control group. Also, immunoreactivity of caspase 3, as marker of apoptosis increased in $\mathrm{CP}$ treated mice. Administration of NC in $\mathrm{CP}$ treated mice revealed reduce oxidative stress, histopathological change and apoptosis which induced by $\mathrm{CP}$. The findings of this study considerably showed antioxidant potential of NC against $\mathrm{CP}$ induced nephrotoxicity.

Acrolein, as one of the metabolites of $\mathrm{CP}$ decrease glutathione and liver microsomal enzyme activities and subsequently leads to toxicity [23] . Blood creatinine measure to evaluate kidney function and glomerular filtration rate [GFR] [24] . In present study, levels of serum creatinine significantly increased in CP-treated mice, which is confirmed renal dysfunction. BUN level was also found to be increased in the CP-treated mice. Elevation of BUN and CREA levels are markers of renal injury, which with NC pretreatment significantly decreased these markers. Our previous studies showed that NC is effective in mitigation hepatotoxicity and testicular toxicity [not publish].

Oxidative stress occurs due to an imbalance between oxidants and antioxidants status [25] and can be determined by evaluation of oxidative stress parameters. GSH as an important antioxidant exist in different redox specie [26] and plays a role in cytoprotection against oxidative injury. In clinical applications, CP induced oxidative stress that has a significant role in the incidence of nephrotoxicity [27] . CP can inhibit antioxidant enzymes activities [glutathione S-transferase; GST, glutathione peroxidase; GPx, superoxide dismutase; SOD, catalase; CAT] and reduce GSH levels [28]. In this study, it was revealed that the administration of $\mathrm{CP}$ has a direct effect on the oxidative markers. The administration of $\mathrm{CP}$ was found to cause a significant increase in MDA level and decrease in the GSH content, which was confirmed with histochemical assay. However, NC administration in CP treated mice showed a significant decrease in MDA level and increase in GSH content that may be due to the antioxidant effects of NC. The expression of antioxidant proteins adjust by $\mathrm{Nrf2}$ as a key protein. $\mathrm{CeO} 2$ able to reduce the translocation Nrf- 2 from cytoplasm into the nucleus and subsequently reduce gene expression of heme oxygenase-1[HO-1]. So Nrf2/HO-1 inhibition were necessary for cytoprotective effect against oxidative effect [29]. NC are able to increase GSH, GPX1, SOD and catalase levels and as a powerful antioxidant agent protect organs against 
oxidative injury [13]. Therefore, protective effect of NC can related to the inhibition of lipid oxidation and reduction of oxidative stress markers.

NC with transition between cerium (III) and cerium (IV) oxidation states, has high oxygen storage capacity and can an excellent choice as a catalyst [30]. Also, NC with having SOD mimetic activity scavenge free radicals and has regenerative role [31]. Additionally, it has reported that NC convert superoxide radicals to peroxide and then intermediately to peroxo-complexes [32]. Reaction of peroxide with NC miss formation of this peroxo-complex [33] $\mathrm{CeO}_{2}$ nanoparticles have been reported to effectively protect mammalian cells against ROS-induced oxidative stress injury [34]. On the other hand, kidney is as a main organ for uptake of NC after liver and spleen [35]. NC accumulate in the plasma membrane and mitochondrial outer membrane of organs [36] and increases cellular resistance against exogenous oxidative stress [37]. Regenerative and therapeutic potential of NC reported in hepatotoxicity [13], brain toxicity [38], radiation-induced gastrointestinal epithelium injury [39], radiation-induced pneumonitis [40]. Consistent with these studies, our study demonstrate nephroprotection of nanoceria against chemotherapy. Although many studies have found antioxidant and cytoprotective effects of nanoceria, studies have also shown a reverse result [41,42]. The different effects of NC are related to differences in size, shape, dose, method of preparation and the surface charges during the synthesis process affect at findings [43, 44] In our study, NC with anti-oxidative properties confirmed that have protective effect against oxidative stress and free radicals.

Nanoceria decrease apoptosis with inhibition of programmed cell death pathway through the effect on the production of free radicals [45] The important finding of this study is that NC significantly inhibits apoptosis via decrease immunoreactivity of caspase-3 in CP-induced apoptosis. $\mathrm{CP}$ with generation oxidative stress, product crosslinks in DNA-DNA and DNA-protein and then cause DNA damage [5] . Kwon et al. have been found NC are mainly localize in mitochondria, mitigate oxidative stress and subsequently mitochondrial damage and suppress cell death [46]. Also, NC with down-regulating expression of apoptosis signaling pathways have protective effect on organs [47] The activation of caspases induce apoptosis which cleave intracellular proteins [48]. Nanoceria is able to decrease caspase- 8 mRNA expression and caspases- 9 and -3 activity [47] . In the present study, CP significantly increased apoptosis in renal epithelial tubular cells in cortex and medulla area, whereas treatment with NC significantly decreased apoptosis. These findings clearly indicated the potential anti-apoptosis property of NC against $\mathrm{CP}$ therapy.

Chemotherapeutic effect of NC proved against doxorubicin. Furthermore, NC enhance anti-tumoral activity of doxorubicin and increase apoptosis in cancer cells. Also, they were exhibited that NC have cytotoxic effects. But co-treatment cancer cells with doxorubicin and NC showed synergistic effects [49]. In our pilot study, we saw cytotoxic effect of NC in dose of $5 \mathrm{mg} / \mathrm{kg}$ for 7 days, and co-treatment NC and CP markley decreased oxidative stress markers, renal injury markers, histopathological and apoptosis in kidney [not publish]. Akhtar et al. investigated effect of NC with 20,50, 100 and $200 \mu \mathrm{g} \mathrm{mL}$ concentrations on oxidative stress in in vitro condition. They have shown NC is no effect on cell death. Furthermore, NC with increase of GSH was maintained cell viability [50].

Khaksar et al. showed NC with $35 \mathrm{mg} / \mathrm{kg}$ daily for two weeks have protective effect against diazinoninduced pancreatic damage. They proved NC can decrease oxidative stress and apoptosis [caspase 3 and 9] [51]. Serebrovska et al. showed NC with dosage of $0.6 \mathrm{mg} / \mathrm{kg}$ for 4 times during the study have antiinflammatory and anti-oxidant property. They treat $\mathrm{NC}$ with orogastric catheter [52]. In present study, we investigate the ability of nanoceria in decrease oxidative stress parameter, renal injury indexes, apoptosis and improved nephrotoxicity in CP treated mice with injection $\mathrm{NC}$ with $100 \mu \mathrm{g} / \mathrm{kg}$ for 3 times via intraperitonealy.

The most important limitation of this study was assessment anti-inflammatory property of this extract.

\section{CONCLUSION}

In summary, this study shows protective effect of cerium oxide nanoparticles pretreatment against CPinduced nephrotoxicity. NC with anti-oxidant and anti-apoptotic properties attenuates renal injury. The antiapoptosis potential of NC might be due to its antioxidant property. These results may be helpful for more application of nanoceria in biomedical fields in the future.

\section{MATERIALS AND METHODS}

\subsection{Animals}

Thirty two male BALB/c mice, weighing 25-30 g were prepared by the Institutional Animal Care and ethics Committee of the Medical science of Mazandaran University, Sari, Iran [ID: 
IR.MAZUMS.REC.1395.S222]. For adapting to the experiment environment, the animals were maintained on a 12 hours light: dark cycle and $20-25^{\circ} \mathrm{C}$ for one week. They had free access to food and water during the study period.

\subsection{Study design}

In this study, the animals were randomly divided into 4 groups of 8 animals each group.

- Group I as the control and were received normal saline.

- Group II [NC] were received NC at a dose of $100 \mu \mathrm{g} / \mathrm{kg}$ by intraperitonealy for 3 consecutive days.

- Group III [CP] received a single dose of CP [200 mg/ $\mathrm{kg}$ ] intraperitoneally on the 3th day,

- Group IV [NC+CP] received NC and CP by the same dose of II \& III groups. NC was administrated daily for three consecutive days before $\mathrm{CP}$ injection.

The doses of NC were selected according to pilot study and CP were selected according to previous studies [53]. Both drugs were dissolved in normal saline. The sixth day of the study, serum biochemical, histochemical, histopathological and immunohistochemical assays were evaluated.

\subsection{Specimen collections}

The animals were anesthetized with ketamine $[50 \mathrm{mg} / \mathrm{kg}]$ and xylazine $[5 \mathrm{mg} / \mathrm{kg}]$ three days after drug administration, blood samples were collected from the heart. Serum were separated from coagulated blood with $3000 \times \mathrm{g}$ for $15 \mathrm{~min}$, and stored at $-20^{\circ} \mathrm{C}$ for evaluating serum CREA and BUN. Then animals were sacrificed and kidneys were immediately removed. One of the kidneys washed with cold phosphate buffer saline [PBS] and weighed for histochemical evaluation, other kidney fixed in $10 \%$ buffer formalin for histopathological and immunohistochemical assays.

\subsection{Measurement of malondialdehyde (MDA)}

MDA or Lipid peroxidation was measured as previous standard method. Kidney sample was homogenized. Then, $0.1 \mathrm{~mL}$ of this sample, $1 \mathrm{~mL}$ of $0.6 \%$ 2-thiobarbituric acid, $3 \mathrm{~mL}$ of $1 \%$ phosphoric acid0.1 mL of distilled water were mixed together. After $45 \mathrm{~min}$ boiling in water bath, the mixture was cooled, and then $4 \mathrm{~mL}$ of $\mathrm{n}$-butanol was added to extract the cold thiobarbituric acid reactants. After that, $4 \mathrm{~mL}$ of $\mathrm{n}$ butanol was added, and the samples were centrifuged at $3000 \times g$ for 5 min for separating butanol layer. Nbutanol layer optical density was determined by spectrophotometry. A standard curve of MDA was created. MDA concentration was expressed as $\mu \mathrm{g} / \mathrm{mg}$ protein.

\subsection{Measurement of glutathione [GSH] content}

Content of the glutathione in the samples was determined by spectrophotometer [UV-1601 PC, Shimadzu, Japan] with 5,5'-dithiobis-2-nitrobenzoic acid [DTNB] as an indicator at $412 \mathrm{~nm}$ and expressed as $\mu \mathrm{M}$.

\subsection{Serum biochemical assay}

The blood urea nitrogen [BUN] and CREA were analyzed by spectrophotometry using the quantitative detection kit, Pars Azmoon, Cat. No. 1400009 and 1400 029, IRAN.

\subsection{Histopathological assay}

For histopathological assay and to determine the effect of $\mathrm{CP}$ and NC on kidney, samples were fixed in $10 \%[\mathrm{w} / \mathrm{v}]$ buffer formalin for 24 hours. After processing and embedding, sections with $5 \mu \mathrm{m}$ thickness stained with periodic acid-Schiff [PAS] for evaluation of tubular atrophy and then examined microscopically. Degeneration, interstitial expansion with leukocytes infiltrated, tubular and glomeruli atrophy, thickening of the basement membrane, tubular epithelial cell detachment, pyknotic nuclei of renal epithelium and the appearance of protein columna [penetration of protein] parameters were scored. As a final point, tubular damage (in 5 fields/each section) was scored by using the percentage of cortical tubules that showing epithelial necrosis: 0 index; $<25 \%$ damage was assigned $1 ; 25 \%-50 \%$ damage was assigned 2; $50 \%-75 \%$ damage was assigned 3 and $>75 \%$ damage was assigned a 4 index [54]. All the histological studies were evaluated by a histologist as blind under light microscope (Nikon 200). 


\subsection{Immunohistochemical assay}

Immunohistochemical technique was performed according to the instructions kit manufacturer [Abcam Company, USA]. At first sections of tissues were deparaffinized with xylene and then rehydrated in alcohol series. After that, they were incubated by $0.3 \% \mathrm{H}_{2} \mathrm{O}_{2}$ in methanol to block endogenous peroxidase activity for 15 minutes. After this steps, the tissue sections were incubated with protein blocker for 10 minutes. After incubation at $4^{\circ} \mathrm{C}$ overnight with primary antibodies [anti-caspase 3 rabbit polyclonal antibody, 1:100 in PBS, $\mathrm{v} / \mathrm{v}$, Abcam, Lat: GR224831-2] at $4^{\circ} \mathrm{C}$ overnight, serial sections of tissues were intubated with secondary antibody conjugated with horseradish peroxidase [Mouse and Rabbit Specific HRP/DAB, Abcam, Lat: GR2623314-4] for 20 minutes, sections were incubated with diaminobenzidine tetrahydrochloride for 5 minutes [55]. Then the slides were dehydrated in alcohol series. Finally, all the slides were assessed under light microscope with a magnification of $\times 40$. For the quantitative analysis, immunohistochemical photomicrographs were assassed using MacBiophotonics Image J 1.41a software by densitometry method. The positive staining severity was assessed as the ratio of the stained area to the entire field assessment.

\subsection{Statistical analysis}

Statistical data analysis was done using SPSS 19 version (Chicago, USA). All of the data are expressed as mean \pm standard deviation $[\mathrm{M} \pm \mathrm{SD}]$. Different groups were compared with each other by using One-Way ANOVA test. $p<0.05$ was considered statistically significant.

Acknowledgements: This research was supported by Student Research Committee and Molecular and Cell Biology Research Center, Faculty of Medicine, Mazandaran University of Medical Sciences, Sari, Iran [grant \# IR.MAZUMS.REC.1395.S222].

Author contributions: Concept - SJ.H., F.T.A.; Design - F.T.A., SJ.H.; Supervision - F.T.A., SJ.H.; Resource - F.T.A., SJ.H.; Materials - F.T.A.; Data Collection and/or Processing - M.H., S.Y.B.; Analysis and/or Interpretation - F.T.A.; Literature Search - SJ.H., F.T.A., M.H., S.Y.B.; Writing - F.T.A.; Critical Reviews - SJ.H., F.T.A., M.H., S.Y.B.

Conflict of interest statement: There is no conflict of interest in this study and publication.

\section{REFERENCES}

[1] Unnikrishnan A, Glover S, Norkina O, Wingard J, Norkin M. Complete resolution of severe ulcerative colitis after haploidentical hematopoietic stem cell transplantation followed by post-transplant high-dose cyclophosphamide. Bone Marrow Transplant. 2017; 52: 1204-1205.

[2] Lim SR, Hyun SH, Lee SG, Kim JY, Kim SH, Park SJ, Moon KS, Sul D, Kim DH, Choi HK. Potential urinary biomarkers of nephrotoxicity in cyclophosphamide-treated rats investigated by NMR-based metabolic profiling. J Biochem Mol Toxicol. 2017; 31(3): e21871

[3] Wahlang B, Falkner KC, Cave MC, Prough RA. Chapter One-Role of Cytochrome P450 Monooxygenase in Carcinogen and Chemotherapeutic Drug Metabolism. Adv Pharmacol. 2015; 74: 1-33.

[4] Zarei M, Shivanandappa T. Amelioration of cyclophosphamide-induced hepatotoxicity by the root extract of Decalepis hamiltonii in mice. Food Chem Toxicol. 2013; 57:179-184.

[5] Bhattacharjee A, Basu A, Ghosh P, Biswas J, Bhattacharya S. Protective effect of Selenium nanoparticle against cyclophosphamide induced hepatotoxicity and genotoxicity in Swiss albino mice. J Biomater Appl. 2014; 29(2): 303317

[6] Sharma S, Sharma P, Kulurkar P, Singh D, Kumar D, Patial V. Iridoid glycosides fraction from Picrorhiza kurroa attenuates cyclophosphamide-induced renal toxicity and peripheral neuropathy via PPAR- $\gamma$ mediated inhibition of inflammation and apoptosis. Phytomedicine. 2017; 36:108-117.

[7] Ruggiero A, Ferrara P, Attinà G, Rizzo D, Riccardi R. Renal toxicity and chemotherapy in children with cancer nephrotoxicity and cancer treatment. Br J Clin Pharmacol. 2017. 83:2605-2614.

[8] Goudarzi M, Kalantari H, Kalantar M, Foruozandeh H. Protective effects of hydroalcoholic extract of Capparis spinosa L. against cyclophosphamide-induced nephrotoxicity in mice. Toxicol. Lett. 2016; 258: S283-S284.

[9] Gagnon J, Fromm KM. Toxicity and protective effects of cerium oxide nanoparticles (nanoceria) depending on their preparation method, particle size, cell type, and exposure route. Eur J Inorg Chem. 2015; 2015(27): 4510-4517.

[10] Liu T, Li L, Teng X, Huang X, Liu H, Chen D, Ren J, He J, Tang F. Single and repeated dose toxicity of mesoporous hollow silica nanoparticles in intravenously exposed mice. Biomaterials. 2011; 32(6): 1657-1668. 
[11] Korsvik C, Patil S, Seal S, Self WT. Superoxide dismutase mimetic properties exhibited by vacancy engineered ceria nanoparticles. Chem Commun (Camb). 2007; 10: 1056-1058.

[12] Pirmohamed T, Dowding JM, Singh S, Wasserman B, Heckert E, Karakoti AS, King JES, Seal S, Self WT. Nanoceria exhibit redox state-dependent catalase mimetic activity. Chem Commun (Camb). 2010; 46(16): 2736-2738.

[13] Hashem RM, Rashd LA, Hashem KS, Soliman HM. Cerium oxide nanoparticles alleviate oxidative stress and decreases Nrf-2/HO-1 in D-GALN/LPS induced hepatotoxicity. Biomed Pharmacother.2015; 73:80-86.

[14] González-Flores D, De Nicola M, Bruni E, Caputo F, Rodríguez AB, Pariente JA, Ghibelli L. Nanoceria protects from alterations in oxidative metabolism and calcium overloads induced by TNFa and cycloheximide in U937 cells: pharmacological potential of nanoparticles. Mol Cell Biochem. 2014; 397(1-2): 245-253.

[15] Forest V, Leclerc L, Hochepied J-F, Trouvé A, Sarry G, Pourchez J. Impact of cerium oxide nanoparticles shape on their in vitro cellular toxicity. Toxicol In Vitro. 2017; 38:136-141.

[16] Xu P, Maidment 3rd B, Antonic V, Jackson I, Das S, Zodda A,Zhang x, Seal S, Vujaskovic Z. Cerium Oxide Nanoparticles: A Potential Medical Countermeasure to Mitigate Radiation-Induced Lung Injury in CBA/J Mice. Radiat Res.2016; 185(5): 516-526.

[17] Ouyang Z, Mainali MK, Sinha N, Strack G, Altundal Y, Hao Y, Winningham TA, Sajo E, Celli J, Ngwa W. Potential of using cerium oxide nanoparticles for protecting healthy tissue during accelerated partial breast irradiation (APBI). Phys Med. 2016; 32(4): 631-635.

[18] Sack M, Alili L, Karaman E, Das S, Gupta A, Seal S,Brenneisen P. Combination of conventional chemotherapeutics with redox-active cerium oxide nanoparticles - A novel aspect in cancer therapy. Mol Cancer Ther. 2014; 13(7): 17401749 .

[19] Chen S, Hou Y, Cheng G, Zhang C, Wang S, Zhang J. Cerium oxide nanoparticles protect endothelial cells from apoptosis induced by oxidative stress. Biol Trace Elem Res. 2013; 154(1): 156-166.

[20] Celardo I, De Nicola M, Mandoli C, Pedersen JZ, Traversa E, Ghibelli L. Ce3+ ions determine redox-dependent antiapoptotic effect of cerium oxide nanoparticles. ACS Nano. 2011; 5(6): 4537-4549.

[21] Mikyšková R, Indrová M, Vlková V, Bieblová J, Šímová J, Paračková Z, Piasecka EP, Rossowska J, Reinis M . DNA demethylating agent 5-azacytidine inhibits myeloid-derived suppressor cells induced by tumor growth and cyclophosphamide treatment. J Leukoc Biol. 2014; 95 743-753. (5) .

[22] Murali VP, Kuttan G. Curculigo orchioides Gaertn Effectively Ameliorates the Uro-and Nephrotoxicities Induced by Cyclophosphamide Administration in Experimental Animals. Integr Cancer Ther.2016; 15(2): 205-215.

[23] Huang Z, Roy P, Waxman DJ. Role of human liver microsomal CYP3A4 and CYP2B6 in catalyzing Ndechloroethylation of cyclophosphamide and ifosfamide. Biochem Pharmacol. 2000; 59(8): 961-972.

[24] Lamb EJ, Brettell EA, Cockwell P, Dalton N, Deeks JJ, Harris K,Higgins T, Kalra PA, Khunti K, Loud F, Ottridge RS, Sharpe CC, Sitch AJ, Stevens PE, Sutton AJ, Taal MW . The eGFR-C study: accuracy of glomerular filtration rate (GFR) estimation using creatinine and cystatin $C$ and albuminuria for monitoring disease progression in patients with stage 3 chronic kidney disease-prospective longitudinal study in a multiethnic population. BMC Nephrol. 2014; 15(1): 13.

[25] Guney T, Kanat İF, Alkan A, Alisik M, Akinci S, Silay K, Neselioglu S, Dilek I, Erel O. Assessment of serum thiol/disulfide homeostasis in multiple myeloma patients by a new method. REDOX REP. 2017; 22(6): 246-251.

[26] Aquilano K, Baldelli S, Ciriolo MR. Glutathione: new roles in redox signaling for an old antioxidant. Front Pharmacol. 2014; 5:196.

[27] Singh JC, Mamtani A, Barrio A, Morrow M, Sugarman S, Jones LW, Yu AF, Argolo D, Smyth LM, Modi S, Schweber S, Boafo C, Patil S, Norton L, Baselga J, Hudis CA, Dang C. Pathologic Complete response with neoadjuvant Doxorubicin and Cyclophosphamide followed by Paclitaxel with Trastuzumab and Pertuzumab in patients with HER2-positive early stage breast cancer: A single center experience. Oncologist. 2017; 22(2): 139-143.

[28] Sheweita SA, El-Hosseiny LS, Nashashibi MA. Protective effects of essential oils as natural antioxidants against hepatotoxicity induced by cyclophosphamide in mice. PLoS One. 2016; 11(11): e0165667.

[29] Zhang H, Liu Y-y, Jiang Q, Li K-r, Zhao Y-x, Cao C,Yao J. Salvianolic acid A protects RPE cells against oxidative stress through activation of Nrf2/HO-1 signaling. Free Radic Biol Med. 2014; 69:219-228.

[30] Reinhardt K, Winkler H. Cerium mischmetal, cerium alloys, and cerium compounds. Ullmann's encyclopedia of industrial chemistry. 2002.

[31] Heckert EG, Karakoti AS, Seal S, Self WT. The role of cerium redox state in the SOD mimetic activity of nanoceria. Biomaterials. 2008; 29(18): 2705-2709.

[32] Scholes F, Hughes A, Hardin S, Lynch P, Miller P. Influence of hydrogen peroxide in the preparation of nanocrystalline ceria. Chem. Mater. 2007; 19(9): 2321-2328.

[33] Guzman J, Carrettin S, Corma A. Spectroscopic evidence for the supply of reactive oxygen during CO oxidation catalyzed by gold supported on nanocrystalline CeO2. J Am Chem Soc. 2005; 127(10): 3286-3287. 
[34] Karakoti A, Singh S, Dowding JM, Seal S, Self WT. Redox-active radical scavenging nanomaterials. Chem Soc Rev. 2010; 39(11): 4422-4432.

[35] Yokel RA, Unrine JM, Wu P, Wang B, Grulke EA. Nanoceria biodistribution and retention in the rat after its intravenous administration are not greatly influenced by dosing schedule, dose, or particle shape. Environ Sci Nano. $2014 ; 1(6)$ :

[36] Dowding J, Song W, Bossy K, Karakoti A, Kumar A, Kim A,Bossy B, Seal S, Ellisman MH, Perkins G, Self WT, BossyWetzel E. Cerium oxide nanoparticles protect against $A \beta$-induced mitochondrial fragmentation and neuronal cell death. Cell Death Differ. 2014; 21(10): 1622-1632.

[37] Xia T, Kovochich M, Liong M, Mädler L, Gilbert B, Shi H,Yeh JI, Zink JI, Nel AE. Comparison of the mechanism of toxicity of zinc oxide and cerium oxide nanoparticles based on dissolution and oxidative stress properties. ACS nano. 2008; 2(10): 2121-2134.

[38] Schubert D, Dargusch R, Raitano J, Chan S-W. Cerium and yttrium oxide nanoparticles are neuroprotective. Biochem Biophys Res Commun. 2006; 342(1): 86-91.

[39] Colon J, Hsieh N, Ferguson A, Kupelian P, Seal S, Jenkins DW, Baker CH. Cerium oxide nanoparticles protect gastrointestinal epithelium from radiation-induced damage by reduction of reactive oxygen species and upregulation of superoxide dismutase 2. Nanomed Nanotech Biol Med (Other). 2010; 6(5): 698-705.

[40] Colon J, Herrera L, Smith J, Patil S, Komanski C, Kupelian P, Seal S, Jenkins W, Baker CH. Protection from radiationinduced pneumonitis using cerium oxide nanoparticles. Nanomed Nanotech Biol Med (Other) .2009; 5(2): 225-231.

[41] Cheng G, Guo W, Han L, Chen E, Kong L, Wang L, Ai W, Song N, Li H, Chen H. Cerium oxide nanoparticles induce cytotoxicity in human hepatoma SMMC-7721 cells via oxidative stress and the activation of MAPK signaling pathways. Toxicol In Vitro. 2013; 27(3): 1082-1088.

[42] Kumari M, Singh SP, Chinde S, Rahman MF, Mahboob M, Grover P. Toxicity study of cerium oxide nanoparticles in human neuroblastoma cells. Int J Toxicol. 2014; 33(2): 86-97.

[43] Asati A, Santra S, Kaittanis C, Perez JM. Surface-charge-dependent cell localization and cytotoxicity of cerium oxide nanoparticles. ACS nano. 2010; 4(9): 5321-5331.

[44] Grulke E, Reed K, Beck M, Huang X, Cormack A, Seal S. Nanoceria: factors affecting its pro-and anti-oxidant properties. Environ Sci Nano. 2014; 1(5): 429-444.

[45] Becker S, Soukup J, Gallagher J. Differential particulate air pollution induced oxidant stress in human granulocytes, monocytes and alveolar macrophages. Toxicol In Vitro. 2002; 16(3): 209-218.

[46] Kwon HJ, Cha M-Y, Kim D, Kim DK, Soh M, Shin K, Hyeon T, Mook-Jung I. Mitochondria-targeting ceria nanoparticles as antioxidants for Alzheimer's disease. ACS Nano. 2016; 10(2): 2860-2870.

[47] Kong L, Cai X, Zhou X, Wong LL, Karakoti AS, Seal S, McGinnis JF. Nanoceria extend photoreceptor cell lifespan in tubby mice by modulation of apoptosis/survival signaling pathways. Neurobiol Dis. 2011; 42(3): 514-523.

[48] Zhang X, Zhu Y, Duan W, Feng C, He X. Allicin induces apoptosis of the MGC-803 human gastric carcinoma cell line through the p38 mitogen-activated protein kinase/caspase-3 signaling pathway. Mol Med Rep. 2015; 11(4): 27552760.

[49] Das J, Choi Y-J, Han JW, Reza AMMT, Kim J-H. Nanoceria-mediated delivery of doxorubicin enhances the antitumour efficiency in ovarian cancer cells via apoptosis. Sci Rep. 2017; 7(1): 9513.

[50] Akhtar MJ, Ahamed M, Alhadlaq HA, Khan MM, Alrokayan SA. Glutathione replenishing potential of CeO 2 nanoparticles in human breast and fibrosarcoma cells. J Colloid Interface Sci. 2015; 453 21-27.

[51] Khaksar MR, Rahimifard M, Baeeri M, Maqbool F, Navaei-Nigjeh M, Hassani S, Moeini-Nodeh S, Kebriaeezadeh A, Abdollahi M. Protective effects of cerium oxide and yttrium oxide nanoparticles on reduction of oxidative stress induced by sub-acute exposure to diazinon in the rat pancreas. J Trace Elem Med Biol. 2017; 41:79-90.

[52] Serebrovska Z, Swanson R, Portnichenko V, Shysh A, Pavlovich S, Tumanovska L,Dorovskych A, Lysenko V, Tertykh V, Bolbukh Y, Dosenko V. Anti-inflammatory and antioxidant effect of cerium dioxide nanoparticles immobilized on the surface of silica nanoparticles in rat experimental pneumonia. Biomed Pharmacother. 2017; 92:69-77.

[53] Mansour DF, Salama AA, Hegazy RR, Omara EA, Nada SA. Whey protein isolate protects against cyclophosphamide-induced acute liver and kidney damage in rats. J appl pharm sci. 2017; 7(06): 111-120.

[54] Ghabaee DNZ, Amiri FT, Moghaddam AE, Khalatbary AR, Zargari M. Administration of zinc against arsenicinduced nephrotoxicity during gestation and lactation in rat model. J Nephropathol. 2017; 6(2): 74.

[55] Naeimi RA, Amiri FT, Khalatbary AR, Ghasemi A, Zargari M, Ghesemi M, Hosseinimehr SJ. Atorvastatin mitigates testicular injuries induced by ionizing radiation in mice. Reproductive Toxicol. 2017; 72: 115-122. 